\title{
Quality of PMTCT Services in Gebretsadiq Shawo Memorial Hospital, Kafa Zone, South West Ethiopia: A Descriptive Study
}

\author{
Negalign Berhanu Bayou*, Yohannes Ejigu Tsehay \\ Department of Health Services Management, College of Public Health and Medical Sciences, Jimma University, \\ Jimma, Ethiopia \\ Email: negenu@gmail.com, ${ }^{*}$ negalign.berhanu@ju.edu.et, yohannesejigu@gmail.com, \\ yohannesejigu@yahoo.com, yohannes.ejigu@ju.edu.et
}

Received 11 April 2015; accepted 2 May 2015; published 8 May 2015

Copyright (C) 2015 by authors and OALib.

This work is licensed under the Creative Commons Attribution International License (CC BY). http://creativecommons.org/licenses/by/4.0/

(c) (i) Open Access

\section{Abstract}

Background: Worldwide, an estimated 2.3 million children under the age of 15 are HIV positive. The main source of HIV infection in children is vertical transmission of HIV from mother-to-child during pregnancy, labor and delivery, or breastfeeding. Prevention of Mother-to-Child Transmission of HIV has been expanded in accelerated fashion throughout Ethiopia with all public hospitals and health centers providing the services. However, published studies on the services' provision in the country are generally limited. If at all, they did not comprehensively examine quality of the services. Objective: The study aimed to assess the quality of Prevention of Mother-to-Child Transmission of HIV services in Gebretsadiq Shawo Memorial Hospital in Kafa Zone, Southwest Ethiopia. Methods: Facility based cross-sectional study involving both quantitative and qualitative methods was conducted in September 2012. A total of 311 pregnant mothers were interviewed and a one year (2011) record of PMTCT clients was reviewed and service provision processes were observed for 10 counseling sessions. Donabedian's Structure-Process-Outcome model was used to conceptualize the study. Data were analyzed using SPSS for windows version 17 software. Descriptive statistics were computed to summarize the findings. Results: Almost all of the minimum required resources such as test kits, prophylactic drugs and other supplies were available in the hospital; counselors followed the national guideline in providing HIV counseling and testing services; and most (90\%) of clients were satisfied or very satisfied by the PMTCT services they received. However, from 858 pregnant mothers who visited the ANC clinic in 2011, only 330(38.5\%) were offered HIV pretest counseling, while $281(33 \%)$ were tested. Conclusion: Although clients' satisfaction by PMTCT service is very high, considerable proportion of pregnant mothers who utilize ANC services are not offered HIV counseling and testing services. Therefore, appropriate quality improvement interventions against the missed opportunities are highly recommended.

\footnotetext{
${ }^{*}$ Corresponding author.
}

How to cite this paper: Bayou, N.B. and Tsehay, Y.E. (2015) Quality of PMTCT Services in Gebretsadiq Shawo Memorial Hospital, Kafa Zone, South West Ethiopia: A Descriptive Study. Open Access Library Journal, 2: e1499. 


\title{
Keywords
}

Quality, PMTCT, Kafa, Ethiopia

\author{
Subject Areas: Public Health
}

\section{Introduction}

About 35 million people live with HIV in 2012 of these; 2.3 million are new HIV infections [1]. And an estimated 2.5 million children under the age of fifteen live with HIV. Sub-Saharan Africa in which Ethiopia is located remains most severely affected, accounting for $69 \%$ of the people living with HIV worldwide. In the hardest hit countries of Sub-Saharan Africa, more than $60 \%$ of all new HIV infections are occurring in women, infants, and young children [2]. And over $90 \%$ of new infections in infants and young children occur through mother to child transmission which can occur during pregnancy, birth or through breastfeeding [3].

In Ethiopia, the trend of HIV incidence is decreasing; UNAIDS report shows that Ethiopia is one of the subSaharan countries demonstrating more than a 25\% decline in new HIV infections [2] and 50\% in vertical transmission from 2009 to 2012 [4]. However, prevalence of HIV among reproductive age group (15 to 49) women is still high. About 3\% of pregnant mothers have HIV and estimated 90,311 HIV-positive pregnant women are expected every year. Without any intervention, $30 \%$ to $45 \%$ of children born from HIV positive mothers will acquire HIV infection [5].

Prevention of Mother to Child Transmission of HIV (PMTCT) service has been introduced with the objective of reducing vertical transmission with four major strategies: primary prevention of HIV infections among individuals of child-bearing age; prevention of unintended pregnancies among HIV-positive and HIV-negative females of child-bearing age; prevention of MTCT of HIV and provision of treatment, care and support for women living with HIV including children and families [6] [7]. Notable progress has been made in the global scaleup of PMTCT service, however; there are still significant portion of target populations who couldn't get the service especially in resource limited settings with high burden of HIV/AIDS [8].

Ethiopia has begun implementing PMTCT service 2001 in four pilot hospitals and scaled it up to include most of public hospitals and health centers. It has developed PMTCT implementation guideline in the same year in line with the World Health Organization's (WHO) recommendations, which focuses on opt-in approach and use of single dose Nevirapine (NVP) prophylaxis for the mother and the baby. The guideline was revised in 2007 and in 2012, taking into account the contemporary knowledge and recommendations from the WHO [5]. Currently, the country is implementing option B+ strategy, in which HIV positive pregnant mothers are offered lifelong ART regardless of their CD4 count and immunologic statuses [8].

However, coverage of the PMTCT services persists to be low where $45 \%$ of pregnant mothers do not get HIV counseling and testing services [9]. And a significant number of eligible mothers miss opportunity at each step along the cascade of the PMTCT services (from HIV testing to provision of appropriate prophylactic drugs both for the mothers and exposed children). In 2013, for example, 83\% of eligible mothers attended Antenatal Care (ANC) and almost all were offered HIV testing service, of which, $70 \%$ received the test and only $40 \%$ of HIV positive mothers received ARV prophylaxis [10].

The foundation of infection control is early diagnosis and effective treatment of infected people or patients based on standard procedures [11]. The failure of many countries to reach their targets in preventing and controling infectious diseases is largely due to failure to manage cases adequately, and inconsistent supply of drugs and other related supplies, among others [12].

Several studies [13]-[19] have assessed the determinants of PMTCT services unitization in developing countries. The studies have frequently reported socio-cultural and health system related factors as the factors that influence utilization of the PMTCT services. Socio-cultural factors include cultural practices of the society, educational status of the mother and male partner involvement; and health system related factors such as quality of the services including adequacy of the basic infrastructure, technical competency of service providers and accessibility of the services. 
Successful implementation of evidence-based program guidelines can significantly improve patient safety and quality of care [20] [21] by decreasing inappropriate variation and expediting the application of effective advances to everyday practice. Yet, they have limited effect on changing health workers' behavior. Health workers' adherence to guidelines may be hindered by a variety of barriers. Mostly, they may not simply be familiar with standards because they have not been clearly communicated. They may also lack the necessary supplies or equipment to perform according to standards. Commonly, providers are aware of standards but may hold beliefs or attitudes that inhibit them from adhering to standards [20].

However, published studies on the PMTCT services' provision in Ethiopia are generally limited. Even fewer studies do examine quality of the services. Therefore, this study has investigated the quality of PMTCT services' provision using the Donabedian's Structure-Process-Outcome model of health service quality assessment [22]. The importance of operational research like the present research, to identify priority health and operational problems by producing evidence for planning and decision making to improve health services has been emphasized in the Health Sector Development Plan-IV of Ethiopia [23]. Therefore, this research has generated relevant evidences for the service providers and managers in the hospital and other facilities in the same zone for making locally appropriate decisions that will contribute to improve implementation of PMTCT program.

\section{Methods and Materials}

The study was conducted in Gebretsadiq Shawo Memorial Hospital. It is a zonal public hospital which is located in Southern Nations Nationalities and Peoples Region (SNNPR), Kafa zone, Bonga town; about 470 kilometers Southwest of Addis Ababa, Ethiopia. It provides both preventive and curative services to an estimated population of one million people. A facility based cross-sectional survey was conducted involving both qualitative and quantitative methods in September 2012. For the assessment of clients' satisfaction, we interviewed a total of 311 clients at exit consecutively until the required sample was obtained. A one year (2011) PMTCT registers and delivery service records were reviewed. Adherence of service providers to the national PMTCT guideline was assessed and the volume of clients served, proportion of clients who accepted the PMTCT counseling and testing service, proportion of clients who had HIV positive results and those who got prophylaxis and who were professionally attended during child birth were determined. Observation of HIV counseling sessions was also performed to assess client counselor interaction, adequacy, compliance and quality of the counseling sessions. Accordingly, a total of 10 counseling sessions were randomly selected for this purpose. In addition, facility audit was done to assess the presence of the minimum required resources, including staffing, infrastructure, medicines and supplies. While a structured questionnaire was used for the exit interview, checklists were used for data abstraction from the PMTCT records and as well as for facility audit. The questionnaire was adapted from validated UNAIDS [24] and Family Health International [25] and others were developed by the researchers. All of the tools were pre-tested to check for their validity and applicability in the local context. An one-day training was given to the data collectors and close supervision was made by the researchers to ensure the quality of the data.

Quality of service is multidimensional concept and can be assessed in different ways. This study had employed Donabedian's structure, process outcome model [26] to assess the quality of PMTCT services. Data on availability of minimum required resources to perform PMTCT activities and organizational setup were collected to measure structure quality. Process quality was measured by assessing adherence of the service providers with the National PMTCT Guideline. As satisfaction is one of the desired outcomes of care, satisfaction of clients by the service was taken as outcome measure of quality.

Data were checked for accuracy and completes; then, cleaned and coded and analyzed using SPSS for windows version 17 software. Descriptive statistics such as mean, standard deviation, median and proportions were computed as appropriate to summarize the findings and presented using frequency tables. Qualitative data obtained from resource inventory and direct observation were transcribed, summarized in to major thematic areas and presented in narrative form.

Last, the proposal was has got ethical approval from Jimma University Ethical Review Board. All study participants were informed about the objective and purpose of the study and written consent was obtained before data collection. The study subjects were given the chance to decline the participation or interrupt at any time if they didn't feel comfortable. As HIV is still a stigmatizing condition, first service providers got consent from clients before they were approached by data collectors. In addition, the clients name was not retrieved from clinical registers. 


\section{Results}

\subsection{Socio-Demographic Characteristics of the Respondents}

A total of 311 clients responded to the questionnaire. The age of respondents ranges from 15 to 45 with a mean $( \pm S D)$ age of $25.5( \pm 5.5)$ years. Ninety six percent of them were married and most of them were literate with only $8 \%$ being unable to read and write. More than half (53.4\%) of the respondents were Orthodox Christians followed by Muslims (19.6\%) and Protestants (18\%). Kafa was the major ethnic group which accounted for 69\% of the respondents, followed by Gurage (11\%) and Amhara (9\%). Majority (72\%), of the respondents were urban dwellers. While $69.8 \%$ of the respondents had experienced a total of one or two pregnancies, only $4.2 \%$ had five and more pregnancies (Table 1).

\subsection{Clients' Experience}

Most of the respondents (98\%), knew about the presence of PMTCT service before they came to the hospital for ANC service. The commonest sources of information were health workers which accounted for $72 \%$ of the time, followed by family or friends (17\%). Majority (76.5\%), of the clients got the service in less than 30 minutes time with a range of 2 to 60 minutes. The duration of the counseling sessions ranged from 5 to 60 minutes with a median duration of 20 minutes.

In almost all cases, both pretest and posttest counseling sessions were given by the same counselor and during the counseling sessions no language barrier was reported by majority (87\%), of the respondents. Clients' perception about the benefit of the counseling sessions was positive where $99 \%$ believed that the counseling was beneficial and 96\% said that they would recommend the service to pregnant mothers (Table 2).

Majority (85\%), of the respondents believed that the waiting room was comfortable where they were either very satisfied or satisfied with it. Almost, similar number of clients was satisfied by the counseling room's comfort and privacy during counseling. Regarding the waiting time to see the PMTCT counselor, 38.6\% of clients were very satisfied and 54\% were just satisfied. More than $80 \%$ of the clients were either satisfied or very satisfied with the adequacy of the duration of the counseling session (Table 3).

Regarding the counselors characteristics, most clients believed that the counselor was respectful (94\%) and trustworthy (90\%). Moreover, most of them were satisfied by the counselors' explanation during counseling and his/her overall competency. When clients were asked to rate their satisfaction by the overall PMTCT services provision, about $90 \%$ of them were either satisfied or very satisfied (Table 4).

\subsection{Observation of Pre and Post Test Counseling Sessions}

In all of the 10 observations that were made, the counselor had received the women in welcoming manner and created a trusting or supportive rapport with the women. It was observed that the counselor listened to women's ideas and concerns in eight of the 10 sessions; and invited them to ask questions in six sessions. The counselor had attempted to respond to each of the questions in all of these six sessions.

In all of the sessions, the counselor had avoided judgment or disapproval; treated women with empathy, dignity, and respect; used language and words that could be easily understood by the women and; maintained privacy. The counselor checked to be sure that the women understood the information provided in eight of the 10 observed sessions.

Regarding pretest counseling, the counselor had introduced and oriented the session to the women, prepared them well for the HIV test, explored options for reducing risk and assessed them for possible risks in all of the observed sessions. Post-test counseling for negative results was performed similarly in all of the observed sessions. Negative HIV-test results were provided, risk-reduction plan was negotiated, support for risk-reduction plan was identified; disclosure and partner referral was negotiated and, the importance of retesting following window period was discussed in all sessions.

However, the counselors didn't give enough time for the counseling sessions which was by far lower than the recommended time. Moreover, they had repeatedly been missing some important components in the counseling manual during both pretest and posttest counseling sessions.

\subsection{Record Review}

A one year record of ANC clients and delivery registers were reviewed. The review revealed that a total of 858 
Table 1. Socio-demographic characteristics of respondents, quality of PMTCT services in Gebretsadiq Shawo Memorial Hospital, Kafa Zone, South West Ethiopia, September 2012.

\begin{tabular}{|c|c|c|c|}
\hline \multicolumn{2}{|c|}{ Characteristics $(n=311)$} & \multirow{2}{*}{$\begin{array}{c}\text { Frequency } \\
60\end{array}$} & \multirow{2}{*}{$\begin{array}{c}\text { Percent } \\
19.3\end{array}$} \\
\hline Age & $15-20$ & & \\
\hline & $21-25$ & 113 & 36.3 \\
\hline & $26-30$ & 92 & 29.6 \\
\hline & $31-35$ & 29 & 9.3 \\
\hline & $36-40$ & 14 & 4.5 \\
\hline & 41 and above & 3 & 1.0 \\
\hline \multirow[t]{5}{*}{ Marital status } & Married & 298 & 96 \\
\hline & Single & 5 & 1.5 \\
\hline & Divorced & 2 & 0.6 \\
\hline & Widowed & 1 & 0.3 \\
\hline & Unmarried couples & 5 & 1.5 \\
\hline \multirow[t]{5}{*}{ Level of education } & Unable to read and write & 25 & 8 \\
\hline & Read and write only & 15 & 4.8 \\
\hline & Grade 1 - 6 & 68 & 21.9 \\
\hline & Grade 7 - 12 & 167 & 53.7 \\
\hline & College/University & 36 & 11.6 \\
\hline \multirow[t]{5}{*}{ Ethnicity } & Kafa & 215 & 69 \\
\hline & Gurage & 33 & 11 \\
\hline & Amhara & 28 & 9 \\
\hline & Oromo & 27 & 8.7 \\
\hline & Others & 8 & 2.5 \\
\hline \multirow[t]{4}{*}{ Religion } & Orthodox & 166 & 53.4 \\
\hline & Muslim & 61 & 19.6 \\
\hline & Protestant & 56 & 18 \\
\hline & Catholic & 28 & 9 \\
\hline \multirow[t]{6}{*}{ Occupation } & Housewife & 113 & 36.3 \\
\hline & Civil servant & 89 & 28.6 \\
\hline & Farmer & 61 & 19.6 \\
\hline & Merchant & 25 & 8 \\
\hline & Student & 21 & 6.8 \\
\hline & No job & 2 & 0.6 \\
\hline \multirow[t]{2}{*}{ Residence } & Urban & 224 & 72 \\
\hline & Rural & 87 & 28 \\
\hline \multirow[t]{3}{*}{ Total pregnancy } & $1-2$ & 217 & 69.8 \\
\hline & $3-4$ & 81 & 26 \\
\hline & 5 and above & 13 & 4.2 \\
\hline
\end{tabular}


Table 2. Waiting time, duration and perceived benefit of counseling session; quality of PMTCT services in Gebretsadiq Shawo Memorial Hospital, Kafa Zone, South West Ethiopia, September 2012.

\begin{tabular}{|c|c|c|c|c|c|c|c|c|c|c|}
\hline \multicolumn{5}{|c|}{ Variable } & & & \multicolumn{3}{|c|}{ Frequency } & Percent \\
\hline \multicolumn{11}{|c|}{ Waiting time to see a service provider } \\
\hline \multicolumn{7}{|c|}{$<30$ minutes } & \multicolumn{3}{|c|}{238} & 76.5 \\
\hline \multicolumn{5}{|c|}{$30-60$ minutes } & & & \multicolumn{3}{|c|}{73} & 23.5 \\
\hline \multicolumn{11}{|c|}{ Median $=10$ minutes; Range $=2-60$ minutes } \\
\hline \multicolumn{11}{|c|}{ Duration of pre and posttest counseling sessions } \\
\hline \multicolumn{7}{|c|}{$>15$ minutes } & \multicolumn{3}{|c|}{86} & 27.5 \\
\hline \multicolumn{7}{|c|}{15 - 30 minutes } & \multicolumn{3}{|c|}{191} & 61.5 \\
\hline \multicolumn{5}{|c|}{ >30minutes } & & & \multicolumn{3}{|c|}{34} & 11.0 \\
\hline \multicolumn{11}{|c|}{ Median $=20$ minutes; Range $=5-60$ minutes } \\
\hline \multicolumn{7}{|c|}{ Pretest and posttest counseling was given by the same counselor } & \multicolumn{3}{|c|}{310} & 99.7 \\
\hline \multicolumn{7}{|c|}{ There was no language barrier } & \multicolumn{3}{|c|}{271} & 87 \\
\hline \multicolumn{7}{|c|}{ The counseling session was beneficial } & \multicolumn{3}{|c|}{308} & 99 \\
\hline \multicolumn{7}{|c|}{ Would recommend the service to others } & \multicolumn{3}{|c|}{301} & 96.8 \\
\hline \multicolumn{11}{|c|}{$\begin{array}{l}\text { Table 3. Client satisfaction with the comfort and privacy of counseling room, and adequacy of counseling session; quality of } \\
\text { PMTCT services in Gebretsadiq Shawo Memorial Hospital, Kafa Zone, South West Ethiopia, September } 2012 .\end{array}$} \\
\hline \multirow{2}{*}{ Item: how do you rate your satisfaction with: } & \multicolumn{2}{|c|}{ Very satisfied } & \multicolumn{2}{|c|}{ Satisfied } & \multicolumn{2}{|c|}{ Neutral } & \multicolumn{2}{|c|}{ Dissatisfied } & \multicolumn{2}{|c|}{ Very dissatisfied } \\
\hline & №. & $\%$ & №. & $\%$ & №. & $\%$ & №. & $\%$ & №. & $\%$ \\
\hline Comfort of the waiting room & 84 & 27.0 & 183 & 58.8 & 30 & 9.6 & 13 & 4.2 & 1 & 0.3 \\
\hline Waiting time & 120 & 38.6 & 168 & 54.0 & 20 & 6.4 & 2 & 0.6 & 1 & 0.3 \\
\hline Comfort of the counseling room & 121 & 38.9 & 160 & 51.4 & 27 & 8.7 & 2 & 0.6 & 1 & 0.3 \\
\hline Privacy of the counseling room & 125 & 40.2 & 152 & 48.9 & 29 & 9.3 & 4 & 1.3 & 1 & 0.3 \\
\hline Adequacy of duration of the counseling session & 164 & 52.7 & 125 & 40.2 & 17 & 5.5 & 3 & 1.0 & 2 & 0.6 \\
\hline
\end{tabular}

Table 4. Client satisfaction by counselor's characteristics, quality of PMTCT services in Gebretsadiq Shawo Memorial Hospital, Kafa Zone, South West Ethiopia, September 2012.

\begin{tabular}{|c|c|c|c|c|c|c|c|c|c|c|}
\hline \multirow{2}{*}{ Item: how do you rate your satisfaction with: } & \multicolumn{2}{|c|}{ Very satisfied } & \multicolumn{2}{|c|}{ Satisfied } & \multicolumn{2}{|c|}{ Neutral } & \multicolumn{2}{|c|}{ Dissatisfied } & \multicolumn{2}{|c|}{ Very dissatisfied } \\
\hline & №. & $\%$ & №. & $\%$ & №. & $\%$ & №. & $\%$ & №. & $\%$ \\
\hline Respectfulness of the counselor & 167 & 53.7 & 127 & 40.8 & 13 & 4.2 & 2 & 0.6 & 2 & 0.6 \\
\hline Trustworthiness of the counselor & 160 & 51.4 & 122 & 39.2 & 19 & 6.1 & 8 & 2.6 & 2 & 0.6 \\
\hline Clarity of the counselor's explanation & 159 & 51.1 & 129 & 41.5 & 19 & 6.1 & 2 & 0.6 & 2 & 0.6 \\
\hline The counselor's competency & 164 & 52.7 & 117 & 37.6 & 28 & 9.0 & 0 & 0 & 2 & 0.6 \\
\hline The overall services & 147 & 47.3 & 133 & 42.8 & 23 & 7.4 & 6 & 1.9 & 2 & 0.6 \\
\hline
\end{tabular}

had at least first ANC visit at the hospital in the year 2011. Out of these mothers, only 330 (38.5\%) were offered pre-test counseling and 281 (85.15\%) got HIV test. Six (2.14\%), mothers tested positive. All of the mothers who were tested were also post-test counseled, regardless of their serostatus. And only 33 partners got tested for HIV and one of them was HIV positive. 
Out of the 858 pregnant mothers who had at least first ANC visit at Gebretsadiq Shawo Memorial hospital, 288 (33.6\%), received labor and delivery services within the hospital. While 115 (39.9\%), of these mothers had HIV test from ANC, of which, three (2.6\%), were known HIV-positive; 173 (60.1\%), were tested during or after delivery. Out of the 173 women who were tested during or after delivery, nine (5.2\%), were positive for HIV. There were 12 HIV-positive women in total, making HIV prevalence rate among pregnant women who were attended their child birth at the hospital in the reference period to be 12 (4.17\%). Three, (25\%), of the 12 positive mothers had already been taking AZT in ANC whereas, the rest, nine (75\%), were given the drug during labor. Infants exposed to 10(83.3\%), positive mothers had received NVP at birth, and all of the positive mothers intended to breastfeed their infants.

\subsection{Resource Inventory}

There was no separate counseling room for PMTCT services provision in the hospital. As a result, the counseling room did not ensure auditory and visual privacy. Otherwise, the labour and delivery as well as the laboratory units were observed to be functional and available for PMTCT services delivery. There were also running water and electricity supplies.

Nevirapine in both its tablet and syrup forms was available neither in ANC nor in delivery room. All of the laboratory supplies that are required for the service provision were available. Similarly, all the basic obstetric care supplies, that is, delivery couches, delivery sets and Oxytocine were available in the hospital. Among the supplies that are required for infection prevention, gloves, aprons and autoclave were available while goggles and sharp boxes were lacking.

Except for pediatric follow-up register and referral linkage slip, all other recording and reporting formats related to PMTCT services were available in the hospital including; monthly summary reporting format, counseling registration book, ANC-PMTCT enrolment register, labour and delivery register, Lab log book, Lab referral slips and ANC-PMTCT appointment card. However, the following job aids and Information, Education, Communication/Behavioral Change Communication (IEC/BCC) materials were not available: PMTCT guideline, PMTCT performance standard, client education materials like brochures and leaflets, PMTCT cue card, and birth preparedness checklist.

\section{Discussion}

Patient or client satisfaction is one of the desired outcomes of health care, a measure of the quality of care, and essential to assessments of quality Satisfaction of clients by the service determine effectiveness of health care [26]. Client satisfaction by the services in a proxy indicator for quality of service and it influences utilization of service as well as compliance with practitioner recommendation [27].

Satisfaction of clients in this study was generally very high; most were either satisfied or very satisfied by all satisfaction items, which may be due to different factors besides genuine rating of clients. First satisfaction of clients could be affected by their HIV test result. Although the proportion of positive and negative test results is not assessed in this study, literatures showed that less than 5\% [28] of clients tested in HCT sites become HIV positive. This means most of the clients receiving the result will be negative for HIV. Hence the result may influence them to be more satisfied. Second most of the clients might not have adequate knowledge on what is expected from the counselors during the counseling sessions.

Different studies have found a significant association between waiting time and satisfaction [29] [30], however, in this study there is no statistically significant association observed between clients waiting time and satisfaction. The reason might be due to relatively short waiting time to see a counselor in all clients which was median time of 10 minutes and clients might have considered the waiting time as reasonable. Hence, direct observation was done to assess the counselors' compliance with the national manual. Although direct observation is considered as the best method to see the whole picture of what providers actually do [31], performance of providers may not represent the routine activity; they might tend to modify their behaviors [32]. Despite these limitations, the observation discovered important gaps in the counselors' performance. During observation, counselors didn't give enough time for the counseling sessions which was by far lower than the recommended time. Besides, some important components in the counseling manual [5] were repeatedly missed both in pretest and posttest counseling sessions.

This study revealed that considerable proportion of ANC clients were missed opportunities. Only one third of 
the 858 pregnant mothers were offered pre-test counseling and only 281 of them got tested for HIV, of which, six mothers tested positive. If we consider that those mothers who were not tested for HIV had similar characteristics with the tested ones, around $12 \mathrm{HIV}$ positive pregnant mothers were missed untested. Thus, considering the national rate of MTCT of HIV [5], three to six children might have been infected already during the reference period. This result is less than a study conducted in Oromia region of Ethiopia, which found $47 \%$ of pregnant women who attended ANC were tested for HIV [33]. HIV testing was better performed during labour and delivery services than ANC in the study setting, although 40\% of delivering mother didn't still get HIV testing service.

Most of the minimum required resources were available in the hospital; however, the counseling room was not separate as opposed to the recommendation of the national guideline [5], it was not sound proof as well making the discussions to be overheard. Since stigma and discrimination is still prevalent, clients may decline to seek the service if they are not sure about the privacy and confidentiality of the service. However, most clients were satisfied by comfortability of the counseling room and privacy as stated in the exit interview results.

This study used different methods to assess the quality of PMTCT services; however, the scope is limited to one hospital which is also an urban setting and this limitation should be considered in applying the finding to different settings. Moreover, the study employed exit interview techniques that could potentially reserve respondents from expressing their true feelings about the services.

\section{Conclusion}

The level of satisfaction with the PMTCT service provision was very high. Most of the minimum required resources to conduct the service were available in the hospital. However, the counseling room was not private and sound proof as recommended by the national PMTCT guideline. Moreover, more than half of pregnant mothers who came to the hospital for ANC service didn't get HIV counseling and testing service as counselors failed to offer them the service and became missed opportunities. Therefore, Gebretsadiq Shawo Memorial Hospital should design appropriate quality improvement interventions to ensure that both the facility and the providers optimally adhered to the national PMTCT implementation guideline.

\section{Competing Interests}

The authors declare that they have no competing interests.

\section{Authors' Contribution}

Both authors contributed equally to this work.

\section{Acknowledgements}

We would like to acknowledge the administration and staff of Gebretsadiq Shawo Memorial hospital.

\section{References}

[1] UNAIDS (2014) Global Report on the Global AIDS Epidemic 2013. www.unaids.org

[2] UNAIDS (2012) UNAIDS Global Report on the Global AIDS Epidemic 2010. www.unaids.org

[3] Federal Democratic Republic of Ethiopia, Federal HIV/AIDS Prevention and Control Office (2014) Report on Progress towards Implementation of the UN Declaration of Commitment on HIV/AIDS 2010, March 2010. http://data.unaids.org/pub/Report/2010/ethiopia_2010_country_progress_report_en.pdf

[4] UNAIDS (2014) 2013 Progress Report on the Global Plan towards the Elimination of New HIV Infections among Children by 2015 and Keeping Their Mothers Alive, November 2013. www.unaids.org/en

[5] FHAPCO and FMOH (2014) Guidelines for Prevention of Mother-to-Child Transmission of HIV Ethiopia, August, 2011. www.fmoh.gov.et

[6] UNFPA (2012) Preventing HIV and Unintended Pregnancies: Strategic Framework (2011-2015). http://www.unfpa.org

[7] WHO, UNICEF (2014) Guidance on Global Scale-Up of the Prevention of Mother-to-Child Transmission of HIV. Towards Universal Access for Women, Infants and Young Children and Eliminating HIV and AIDS among Children. 
http://www.unicef.org/aids/files/PMTCT_enWEBNov26.pdf

[8] WHO (2010) ANTIRETROVIRAL Drugs for Treating G Pregnant Women and Preventing HIV Infection in Infants Recommendations for a Public Health Approach 2010 Version.

[9] FMOH (2014) 2012/13 Annual Performance Report. www.moh.gov.et

[10] FMOH (2013) The National Strategic Plan for Elimination of Mother to Child Transmission of HIV (e-MTCT of HIV).

[11] WHO (2009) Implementing the WHO Policy on TB Infection Control: A Framework to Plan, Implement and Scale-Up TB Infection. www.stoptb.org/.../tb.../TBICImplementationFramework1288971813

[12] RPM Plus (2005) Pharmaceutical Management for Tuberculosis Assessment Manual. Management Sciences for Health, Arlington. www.msh.org/projects/rpmplus/.../FINAL-PMTB

[13] Manzi, M., Zachariah, R., Teck, R., Buhendwa, L., Kazima, J., Bakali, E., et al. (2005) High Acceptability of Voluntary Counselling and HIV-Testing but Unacceptable Loss to Follow up in a Prevention of Mother-to-Child HIV Transmission Programme in Rural Malawi: Scaling-Up Requires a Different Way of Acting. Tropical Medicine \& International Health, 12, 1242-1250. http://dx.doi.org/10.1111/j.1365-3156.2005.01526.x

[14] Taye, T., Susanne, S. and Anders, R. (2011) Strategic Challenges of PMTCT Program Implementation in Oromya Region, Ethiopia. Journal of the International Association of Physicians in AIDS Care (JIAPAC), 10, 187-192. http://dx.doi.org/10.1177/1545109710369935

[15] Painter, T.M., Diaby, K.L., Matia, D.M., Lin, L.S., Sibailly, T.S., Kouassi, M.K., et al. (2004) Women’s Reasons for Not Participating in Follow-Up Visits before Starting Short-Course Antiretroviral Prophylaxis for Prevention of Mother-to-Child Transmission of HIV: Qualitative Interview Study. British Medical Journal, 329, 543. http://dx.doi.org/10.1136/bmj.329.7465.543

[16] Petrie, K.E., Schmidt, S.D., Schwarz, C.E., Koornhof, H.E. and Marais, D. (2007) Knowledge, Attitudes and Practices of Women Regarding the Prevention of Mother-to-Child Transmission (PMTCT) Programme at the Vanguard Community Health Centre, Western Cape-A Pilot Study. South African Journal Clinical Nutrition, 20, 71-75.

[17] London, L., Orner, P.J. and Myer, L. (2008) Even If You're Positive, You Still Have Rights Because You Are a Person: Human Rights and the Reproductive Choice of HIV-Positive Persons. Developing World Bioethics, 8, 11-22. http://dx.doi.org/10.1111/j.1471-8847.2007.00223.x

[18] Peltzer, K., Mosala, T., Shisana, O., Nqueko, A. and Mngqundaniso, N. (2007) Barriers to Prevention of HIV Transmission from Mother to Child (PMTCT) in a Resource-Poor Setting in the Eastern Cape, South Africa. African Journal of Reproductive Health, 11, 57-66. http://dx.doi.org/10.2307/30032488

[19] Gourlay, A., Birdthistle, I., Mburu, G., Iorpenda, K. and Wringe, A. (2013) Barriers and Facilitating Factors to the Uptake of Antiretroviral Drugs for Prevention of Mother-to-Child Transmission of HIV in Sub-Saharan Africa: A Systematic Review. Journal of the International AIDS Society, 16, Article ID: 18588. http://dx.doi.org/10.7448/IAS.16.1.18588

[20] WHO (2006) International Standards for Tuberculosis Care (ISTC). World Health Organization, Geneva.

[21] Berwick, D.M., Calkins, D.R., McCannon, C.J. and Hackbarth, A.D. (2006) The 100,000 Lives Campaign: Setting a Goal and a Deadline for Improving Health Care Quality. JAMA, 295, 324-327. http://dx.doi.org/10.1001/jama.295.3.324

[22] Donabedian, A. (2003) An Introduction to Quality Assurance in Health Care. Oxford University Press, Oxford.

[23] FMOH (2010) Health Sector Development Program IV 2010/11-2014/15. FDRE, Ministry of Health.

[24] UNAIDS (2000) Tools for Evaluating HIV Voluntary Counseling and Testing. Geneva. http://www.unaids.org

[25] Family Health International (2003) Baseline Assessment Tools for Preventing Mother-to-Child Transmission (PMTCT) of HIV/AIDS.

[26] Donabedian, A. (1988) The Quality of Care: How Can It Be Assessed? Journal of the American Medical Association, 260, 1743-1748. http://dx.doi.org/10.1001/jama.1988.03410120089033

[27] Bernhart, M.H., Wiadnyana, I.G., Wihardjo, H. and Pohan, I. (1999) Patient Satisfaction in Developing Countries. Social Science \& Medicine, 48, 989-996. http://dx.doi.org/10.1016/S0277-9536(98)00376-1

[28] Cherinet, Y., Berihu, A., Bekele, A., Biadgilign, S., Taye, B. and Tsegaye, A. (2013) Trend of HIV Prevalence among Pregnant Women Attending Antenatal Care Unit of Bishoftu Hospital, Ethiopia. Ethiopian Medical Journal, 51, 169176.

[29] Westaway, M.S., Rheeder, P., Van Zyl, D.G. and Seager, J.R. (2003) Interpersonal and Organizational Dimensions of Patient Satisfaction: The Moderating Effects of Health Status. International Journal for Quality in Health Care, 15, 337-344. http://dx.doi.org/10.1093/intqhc/mzg042

[30] Andaleeb, S.S. (2001) Service Quality Perceptions and Patient Satisfaction: A Study of Hospitals in Developing Coun- 
tries. Social Science \& Medicine, 52, 1359-1370. http://dx.doi.org/10.1016/S0277-9536(00)00235-5

[31] Huntington, D., Miller, K. and Mensch, B. (1996) The Reliability of the Situation Analysis Observation Guide. Studies in Family Planning, 27, 277-282. http://dx.doi.org/10.2307/2137999

[32] Rethan, J., Westin, S. and Hays, R. (1996) Methods for Quality Assessment General Practice. Family Practice, 13, 468-476. http://dx.doi.org/10.1093/fampra/13.5.468

[33] Balcha, T.T., Lecerof, S.S. and Jeppsson, A.R. (2011) Strategic Challenges of PMTCT Program Implementation in Ethiopia. Journal of the International Association of Physicians in AIDS Care (JIAPAC), 10, 187-192.

http://dx.doi.org/10.1177/1545109710369935

\section{Abbreviations}

AIDS: Acquired Immunodeficiency Syndrome

ANC: Antenatal Care

HIV: Human Immunodeficiency Virus

NVP: Nevirapine

PMTCT: Prevention of Mother to Child Transmission of HIV

UNAIDS: United Nations Program on HIV and AIDS

WHO: World Health Organization 


\section{Annex I. Structured Exit Interview Questionnaire Administered to PMTCT Clients}

Part I. Socio-demographic characteristics of respondents.

\begin{tabular}{|c|c|c|c|}
\hline S. No. & Questions & Category & Remark \\
\hline 101 & Age in years & _ & \\
\hline 102 & Religion & $\begin{array}{l}\text { 1. Orthodox } \\
\text { 2. Muslim } \\
\text { 3. Protestant } \\
\text { 4. Catholic } \\
\text { 5. Other (specify) }\end{array}$ & \\
\hline 103 & Ethnicity & $\begin{array}{l}\text { 1. Kefa } \\
\text { 2. Gurage } \\
\text { 3. Oromo } \\
\text { 4. Amhara } \\
\text { 5. Other specify }\end{array}$ & \\
\hline 104 & Marital status & $\begin{array}{l}\text { 1. Married } \\
\text { 2. Never married } \\
\text { 3. Divorced } \\
\text { 4. Widowed } \\
\text { 5. Unmarried couples }\end{array}$ & \\
\hline 105 & Educational status & $\begin{array}{l}\text { 1. Illiterate } \\
\text { 2. Read and write } \\
\text { 3. Grade1-6 } \\
\text { 4. Grade } 7-12 \\
\text { 5. College/university }\end{array}$ & \\
\hline 106 & Occupation & $\begin{array}{l}\text { 1. House wife } \\
\text { 2. Farmer } \\
\text { 3. Civil servant } \\
\text { 4. Student } \\
\text { 5. Merchant } \\
\text { 6. No job } \\
\text { Others (specify) }\end{array}$ & \\
\hline 107 & Place of residence & $\begin{array}{l}\text { 1. Urban } \\
\text { 2. Rural }\end{array}$ & \\
\hline 108 & Gravidity & & \\
\hline 109 & Average monthly income & & \\
\hline
\end{tabular}

Part 2. Source of information about the PMTCT service and clients experience at the PMTCT site.

\begin{tabular}{|c|c|c|c|}
\hline S. No. & Questions & Category & Remark \\
\hline 201 & Did you know about PMTCT service before? & $\begin{array}{l}\text { Yes } \\
\text { No }\end{array}$ & \\
\hline 202 & If yes, source of information about the PMTCT service & $\begin{array}{l}\text { 1. Health workers/health facility } \\
\text { 2. Mass media } \\
\text { 3. Friends/family } \\
\text { 4. Other (specify) _ }\end{array}$ & \\
\hline 203 & $\begin{array}{l}\text { How long did you wait to see the health care provider? } \\
\text { (in Minutes) }\end{array}$ & __minutes) & \\
\hline 204 & $\begin{array}{l}\text { How much time did the counseling session } \\
\text { (pretest and posttest counseling) took? }\end{array}$ & & \\
\hline 205 & $\begin{array}{l}\text { Was the counseling given by the same counselor } \\
\text { in pretest and post test counseling? }\end{array}$ & $\begin{array}{l}\text { 1. Yes } \\
\text { 2. No }\end{array}$ & \\
\hline 206 & Did the counselor speak the same language as you? & $\begin{array}{l}\text { 1. Yes } \\
\text { 2. No }\end{array}$ & \\
\hline 207 & $\begin{array}{l}\text { Would you have preferred to have a counselor that is? } \\
\text { - Different sex } \\
\text { - Older } \\
\text { - Younger }\end{array}$ & $\begin{array}{l}\text { 1. Yes 2. No } \\
\text { 1. Yes 2. No } \\
\text { 1. Yes 2. No }\end{array}$ & \\
\hline
\end{tabular}




\section{Continued}

208

209
Do you think the counseling and testing service is beneficial?

Would you recommend service to others?
1. Yes

2. No

1. Yes

2. No

Part 3. Satisfaction items.

\begin{tabular}{|c|c|c|c|c|c|c|}
\hline S. No. & Questions & Very dissatisfied & Dissatisfied & Neutral & Satisfied & Very satisfied \\
\hline 301 & $\begin{array}{l}\text { How do you you're your satisfaction } \\
\text { with the waiting room comfort? }\end{array}$ & & & & & \\
\hline 302 & $\begin{array}{l}\text { How do you you're your satisfaction with the } \\
\text { waiting time (within a short period of time)? }\end{array}$ & & & & & \\
\hline 303 & $\begin{array}{l}\text { How do you you're your satisfaction with } \\
\text { the counseling room comfort? }\end{array}$ & & & & & \\
\hline 304 & $\begin{array}{l}\text { How do you you're your satisfaction with } \\
\text { the privacy of the counseling room? }\end{array}$ & & & & & \\
\hline 305 & $\begin{array}{l}\text { How do you you're your satisfaction with } \\
\text { the adequacy of time for counseling? }\end{array}$ & & & & & \\
\hline 306 & $\begin{array}{l}\text { How do you you're your satisfaction with } \\
\text { the counselors respect for you? }\end{array}$ & & & & & \\
\hline 307 & $\begin{array}{l}\text { How do you you're your satisfaction with the service } \\
\text { providers confidentiality and trustworthiness? }\end{array}$ & & & & & \\
\hline 308 & $\begin{array}{l}\text { How do you you're your satisfaction with the } \\
\text { counselors explanation about different issues? }\end{array}$ & & & & & \\
\hline 309 & $\begin{array}{l}\text { How do you you're your satisfaction with the } \\
\text { counselors competence? }\end{array}$ & & & & & \\
\hline 310 & $\begin{array}{l}\text { How do you you're your satisfaction with your } \\
\text { overall satisfaction with the service you received? }\end{array}$ & & & & & \\
\hline
\end{tabular}

